\title{
Impact of Training of Primary Health Care Centers' Vaccinators on Immunization Session Practices in Wasit Governorate, Iraq: Interventional Study
}

Ali Sadiq Amily ${ }^{1}, \mathrm{MBChB}$; Faris Lami ${ }^{2}, \mathrm{MBChB}, \mathrm{PhD}, \mathrm{FFPH}$; Yousef $\mathrm{Khader}^{3}$, BDS, MSc, MSPH, MHPE, FFPH, $\mathrm{ScD}$

${ }^{1}$ Immunization Section, Wasit Directorate of Health, Iraqi Ministry of Health, Kut, Iraq

${ }^{2}$ Department of Community and Family Medicine, College of Medicine, Baghdad University, Baghdad, Iraq

${ }^{3}$ Faculty of Medicine, Jordan University of Science \& Technology, Irbid, Jordan

Corresponding Author:

Ali Sadiq Amily, MBChB

Immunization Section

Wasit Directorate of Health

Iraqi Ministry of Health

Tamooz

Kut

Iraq

Phone: 9647813928919

Email: amily_ali@yahoo.com

\section{Abstract}

Background: Immunization averts more than 2.5 million deaths of children annually. The World Health Organization (WHO) and the United Nations Children's Fund estimates of immunization coverage in Iraq in 2015 revealed a 58\% coverage for the third dose of the diphtheria-tetanus-pertussis vaccine and a 57\% coverage for the measles vaccine. High-quality immunization session practices (ISPs) can ensure safer, more effective vaccination and higher coverage rates.

Objective: The goal of this study was to assess the impact of training of primary health care centers' (PHCs) vaccinators on the quality of ISPs.

Methods: This was an interventional study conducted on 10 (18\%) PHCs in Wasit Governorate. Two PHCs were randomly selected from each health district. ISPs were assessed by direct on-job observation, using modified WHO immunization session checklists. Findings were grouped into seven domains: vaccine and diluent management, cold chain management, session equipment, registration, communication, vaccine preparation and administration, and waste management. The vaccinators were enrolled in a one-day training session using the WHO module, "Managing an Immunization Session", and one month later a second assessment was conducted using the same tools and techniques. We then calculated the median differences of the domains' scores.

Results: A total of 42 vaccinators were trained, with 25 (60\%) of them having graduated from technical health institutes, but only $15(36 \%)$ having had previous training on standard ISPs. Following training, a significant improvement was noticed in three domains: vaccines and diluents management $(P=.01)$, cold chain management $(P=.01)$ and vaccine preparation and administration $(P=.02)$.

Conclusions: The training of the PHCs' vaccinators for a single day was effective in improving some ISPs. We would recommend using this training module, or a more in-depth one, for other PHCs to improve utilization of immunization services.

(JMIR Public Health Surveill 2019;5(4):e14451) doi: 10.2196/14451

\section{KEYWORDS}

immunization; primary health care; intervention; practices; Iraq 


\section{Introduction}

Vaccination is one of the greatest public health achievements [1], with the greatest impact on human health and longevity compared to any other [2]. Apart from safe water, nothing other than vaccination, not even antibiotics, has had such a major effect on the reduction of mortality and on population growth [3]. Globally, vaccines prevent more than 2.5 million deaths of children each year [4], with one good example being the global reduction in deaths from measles by $79 \%$ between 2000 (651,600 deaths) and 2015 (134,200 deaths) [5].

Although vaccines are considered safe, they are not risk-free, and adverse events following vaccination may occasionally occur. Public trust in vaccine safety is key to the success of any vaccination program [1], thus, health care professionals must develop and maintain the highest possible competency with vaccination procedures. However, this process is becoming increasingly difficult due to a lack of resources and due to continuous pressure on professionals' time. Knowledge is vital in maintaining comprehensive vaccination programs and strengthening best practices during daily work, and the goal is to use this knowledge to build vaccinators' abilities and to improve immunization session practices (ISPs) [6].

Unfortunately, in Iraq, enrolling newly assigned vaccinators in routine training courses is not part of their training system, and while this might happen occasionally it is not scheduled. Thus, vaccinators can handle the challenges they may encounter during routine daily work by getting into close contact with senior vaccinators, at their sites, to gain further skills and build up their skills.

In addition to factors related to knowledge, skills, attitudes, and training of health care professionals, another factor that may play a role in strengthening vaccination competence is the vaccination environment. It should be quiet, safe, spacious, warm, private, and soundproof. However, excess amounts of work and staff shortages may weaken this competence [6].

World Health Organization (WHO) and United Nations Children's Fund (UNICEF) estimates of immunization coverage in Iraq in 2015 revealed a 58\% coverage for the third dose of diphtheria-tetanus-pertussis vaccine, a $63 \%$ coverage for the third dose of oral polio vaccine, and a $57 \%$ coverage for the first dose of measles containing vaccine [7] against a 95\% national target for each antigen [8]. Ensuring high quality ISPs can lead to safer and more effective vaccination as well as higher coverage rates. Thus, it is of paramount importance to assess these practices and to ensure they are all the best quality, particularly when, according to our knowledge, such an assessment had never been done before in Iraq or in Wasit governorate.

The aim of this study was to assess ISPs in selected primary health care centers (PHCs) in Wasit governorate and to assess the impact of training of their vaccinators on the quality of ISPs.

\section{Methods}

\section{Study Design and Setting}

This interventional study was conducted in 10 PHCs in Wasit Governorate, one of the 18 governorates in Iraq. Wasit is in eastern Iraq, $160 \mathrm{~km}$ to the south east of the capital, Baghdad. It occupies an area of $17,153 \mathrm{~km}^{2}$, with a total population of 1,149,059. It has six health districts: Kut-1 (10 PHCs), Kut-2 (13 PHCs), Hai (10 PHCs), Suwayrah (13 PHCs), Numaniyah (3 PHCs), and Aziziyah (6 PHCs).

The 10 (18\%) PHCs were selected by simple random sampling from the six health districts in Wasit Governorate. Two PHCs were randomly selected from each health district (except for Numaniyah and Aziziyah districts, as they were instead treated as a single district and only two PHCs were randomly selected from both). All the selected PHCs regularly provide immunization services.

We visited each of these PHCs once to assess ISPs with direct on the job observation, using modified WHO immunization session checklists [9]. Then, the vaccinators were enrolled in a one-day, UNICEF-funded training program using the WHO module Managing an Immunization Session [9]. The same tools and techniques were used again one month later to assess ISPs in the same PHCs.

\section{Immunization Session Checklists}

We developed three checklists using Epi Info 7 (Centers for Disease Control and Prevention [CDC], Atlanta) based on the WHO immunization session checklist [9], the WHO checklists for vaccines and immunization [10], and the national guidelines for vaccines and immunization $[8,11,12]$. The developed checklists were a checklist for setting up the immunization session (see Multimedia Appendix 1), a checklist for the conduct of the immunization session (see Multimedia Appendix 2), and a checklist for concluding the immunization session (see Multimedia Appendix 3). These checklists were used to assess 62 ISPs.

\section{Immunization Session Practices}

ISPs are the tasks a health worker needs to perform to ensure the quality of an immunization session. They covered the following aspects: preparation for the session, communication with clients and caregivers during each encounter, assessment of infants before vaccination, correct technique for giving vaccines, closing the session, and recording data [9]. Each of the 62 ISPs was given a score of one when correctly practiced, or zero if not. For analytic purposes, these ISPs were grouped into seven domains: Vaccine and diluent management (12 ISPs), cold chain management (6 ISPs), session equipment (7 ISPs), card review and registration (14 ISPs), communication with clients and caregivers (4 ISPs), vaccine preparation and administration (14 ISPs), and waste management (5 ISPs).

\section{Questionnaires}

Two questionnaires were developed using Epi Info 7. The first was the vaccinator's questionnaire, which was used to collect data on health care workers' (HCWs) age, gender, level of education (classified as intermediate school, high school, nursing 
school, technical health institute, college of nursing, and nonmedical college), number of years of working in the field of immunization, and if they received any formal training on standard ISPs. The second questionnaire was used to collect information from PHCs, such as the district's name, the number of doctors in the PHC, the number of vaccinators working in the immunization unit, the number of people served by the PHC according to 2016 population, and the average daily number of people receiving vaccinations in the PHC.

\section{Training Program}

Vaccinators in the selected PHCs were enrolled in a one-day training program that was conducted in the hall of the Center for Training and Development-Wasit Directorate of Health. A total of 42 vaccinators from the selected sites were trained after dividing them into two groups, with each group including half the number of vaccinators working in each PHC (in order to not create a shortage in the manpower working in the immunization unit in any of these PHCs on the day of training). The first group received training on Monday, November 28, 2016 and the second on Wednesday, November 30, 2016.

The training material was adopted from the WHO immunization training resource,Managing an Immunization Session [9]. We translated this module into Arabic and presented it as a PowerPoint show supported by three video clips about: (1) how to give the Bacille Calmette-Guerin vaccine to an infant; (2) the correct technique for giving intramuscular injections to infants; and (3) how to manage the immunization session as a whole. The presentation also had many pictures that were adopted from the CDC website.

Ethical approval was obtained from the Public Health Department at Wasit Directorate of Health, and UNICEF funded the training over its two days with an average cost of about 35 United States Dollars per vaccinator.

\section{Statistical Analysis}

First, collected data were entered into Epi Info 7 (because the checklists and questionnaires were developed using the software), and then further processing and analyses were done using Excel (Microsoft, Redmond) to calculate the mean and median scores for each domain. Each single domain had a specific number of ISPs that were each given a score of one when correctly practiced or zero if not. After that, the mean and median for all practices contained in a single domain were calculated, giving a final score for that domain which ranged from 1-0 for the perfect domain and for the least achieving one, respectively. The above calculation was performed twice, once before and another time following the training. Then, the differences between pre- and posttraining domains' scores were calculated and the Wilcoxon signed-rank test was used to determine statistical significance. A $P<.05$ was considered statistically significant.

\section{Results}

The study was conducted among 10 PHCs with 42 vaccinators. A total of $25 / 42$ vaccinators $(60 \%)$ had graduated from technical health institutes (two years following high school). All others had a lower education level, and none were college graduates. Only $15(36 \%)$ of them had previous training on ISPs. The range of years of experience as vaccinators was 1-25 years, with a median of 3 years. Overall, 10 (24\%) of the vaccinators were newly assigned, with less than one year of experience in the field of immunization. The main characteristics of the studied PHCs and vaccinators are shown in Tables 1 and 2, respectively.

Among the 10 studied PHCs, six (60\%) showed a statistically significant improvement in immunization session practices following the training of vaccinators, two (20\%) showed an improvement that was not significant, and the remaining two (20\%) PHCs showed some unexpected decline in their ISP scores (Table 3).

Table 1. Characteristics of 10 primary health care centers in Wasit Governorate, 2016.

\begin{tabular}{|c|c|c|c|c|c|}
\hline Primary health care center & District & Doctors, $\mathrm{n}$ & Vaccinators, $\mathrm{n}$ & Catchment area population, $\mathrm{n}$ & $\begin{array}{l}\text { Vaccinators' density } \\
\text { (vaccinators } / 10,000 \\
\text { people) }\end{array}$ \\
\hline Badr Ul-Kubra & Kut-1 & 3 & 4 & 33,934 & 1.2 \\
\hline Badra & Kut-1 & 4 & 4 & 15,605 & 2.6 \\
\hline Falahiyah & Kut-2 & 0 & 3 & 40,865 & 0.7 \\
\hline Al-Hakiem & Kut-2 & 2 & 3 & 11,500 & 2.6 \\
\hline Muwaffaqiyah & Hai & 3 & 6 & 33,107 & 1.8 \\
\hline Asskary & Hai & 3 & 5 & 22,307 & 2.2 \\
\hline Numaniyah & Numaniyah and Aziziyah & 5 & 11 & 72,403 & 1.5 \\
\hline Ahrar & Numaniyah and Aziziyah & 3 & 3 & 26,588 & 1.1 \\
\hline Mazraa & Suwayrah & 3 & 2 & 10,660 & 1.9 \\
\hline Shuhaymiyah & Suwayrah & 3 & 1 & 19,189 & 0.5 \\
\hline
\end{tabular}


Table 2. Characteristics of vaccinators working in 10 primary health care centers in Wasit Governorate, $2016(\mathrm{~N}=42)$.

\begin{tabular}{ll}
\hline Characteristics & Distribution, $n(\%)$ \\
\hline Sex & $22(52)$ \\
$\quad$ Male & $20(48)$ \\
$\quad$ Female & $25(60)$ \\
Educational status & $14(33)$ \\
$\quad$ Technical health institute & $1(2)$ \\
$\quad$ Nursing school & $2(5)$ \\
$\quad$ High school & $10(24)$ \\
Intermediate school & $20(48)$ \\
Service duration & $12(28)$ \\
$\quad<1$ year & \\
$1-5$ years & $15(36)$ \\
$\quad>5$ years & $27(64)$ \\
Previous training on immunization session practices & \\
Trained & Not trained
\end{tabular}

Table 3. The change in scores of immunization session practices following training of vaccinators in 10 primary health care centers in Wasit Governorate, 2016.

\begin{tabular}{lllll}
\hline Primary health care center & Pretraining, mean (SD) & Posttraining, mean (SD) & Change, mean (SD) & $P$ value \\
\hline Badr Ul-Kubra & $0.73(0.45)$ & $0.63(0.49)$ & $-0.10(0.47)$ & .11 \\
Badra & $0.63(0.49)$ & $0.76(0.43)$ & $0.13(0.50)$ & .045 \\
Falahiyah & $0.71(0.46)$ & $0.68(0.47)$ & $-0.03(0.48)$ & .60 \\
Al-Hakiem & $0.60(0.49)$ & $0.84(0.37)$ & $0.24(0.59)$ & .002 \\
Muwaffaqiyah & $0.68(0.47)$ & $0.84(0.37)$ & $0.16(0.52)$ & .02 \\
Asskary & $0.76(0.43)$ & $0.84(0.37)$ & $0.08(0.49)$ & .20 \\
Numaniyah & $0.56(0.50)$ & $0.66(0.48)$ & $0.10(0.39)$ & .06 \\
Ahrar & $0.60(0.49)$ & $0.94(0.25)$ & $0.34(0.48)$ & $<.001$ \\
Mazraa & $0.53(0.50)$ & $0.92(0.27)$ & $0.39(0.49)$ & $<.001$ \\
Shuhaymiyah & $0.53(0.50)$ & $0.85(0.36)$ & $0.32(0.47)$ & $<.001$ \\
Total & $0.632(0.081)$ & $0.795(0.108)$ & $0.163(0.160)$ & .01 \\
\hline
\end{tabular}

There were varying degrees of improvement among the domains following the training. Three domains that were originally among the lowest scoring showed the most significant improvement, including: vaccine and diluent management, cold chain management, and vaccine preparation and administration. Other domains with higher scores included: session equipment, waste management, and card review and registration. These later domains showed a less remarkable and statistically nonsignificant improvement. Despite originally being a mid-level domain with a mean 0.5 (SD 0.5), communication with clients and caregivers increased only a small, nonsignificant amount following the training (Table 4).

All ISPs, with the percentage of PHCs correctly practicing them as well as the difference following the training, are shown in Table 5. 
Table 4. The change in scores of immunization session practices, by domains, following training of vaccinators in 10 primary health care centers in Wasit Governorate, 2016.

\begin{tabular}{|c|c|c|c|c|c|}
\hline \multirow[t]{2}{*}{ Domain } & \multicolumn{2}{|l|}{ Pretraining } & \multicolumn{2}{|l|}{ Posttraining } & \multirow[t]{2}{*}{$P$ value } \\
\hline & Mean (SD) & Median & Mean (SD) & Median & \\
\hline Vaccine and diluent management & $0.5(0.1)$ & 0.5 & $0.8(0.1)$ & 0.8 & .01 \\
\hline Cold chain management & $0.3(0.2)$ & 0.3 & $0.8(0.3)$ & 1.0 & .01 \\
\hline Session equipment & $0.9(0.1)$ & 0.9 & $0.9(0.1)$ & 0.9 & .26 \\
\hline $\begin{array}{l}\text { Communication with clients and } \\
\text { caregivers }\end{array}$ & $0.5(0.5)$ & 0.4 & $0.6(0.4)$ & 0.6 & .67 \\
\hline Card review and registration & $0.7(0.1)$ & 0.7 & $0.8(0.1)$ & 0.8 & .13 \\
\hline $\begin{array}{l}\text { Vaccine preparation and administra- } \\
\text { tion }\end{array}$ & $0.6(0.1)$ & 0.6 & $0.8(0.1)$ & 0.8 & .02 \\
\hline Waste management & $0.8(0.2)$ & 0.8 & $0.8(0.1)$ & 0.8 & .52 \\
\hline
\end{tabular}


Table 5. Percentage of primary health care centers (PHCs) with standard immunization session practices (ISPs) in Wasit Governorate, 2016

\begin{tabular}{|c|c|c|}
\hline Domains and ISP & $\begin{array}{l}\text { PHCs with pretraining standard } \\
\text { practices }(\%)\end{array}$ & $\begin{array}{l}\text { PHCs with posttraining standard } \\
\text { practices }(\%)\end{array}$ \\
\hline \multicolumn{3}{|l|}{ Vaccine and diluent management } \\
\hline Vaccine quantity checked & 100 & 100 \\
\hline Vaccines out refrigerator in required quantity & 50 & 60 \\
\hline Vaccines out refrigerator in order & 20 & 80 \\
\hline Diluent quantity matched & 50 & 60 \\
\hline Diluent type matched & 90 & 100 \\
\hline Label checked & 10 & 70 \\
\hline Expiry date checked & 10 & 70 \\
\hline $\mathrm{VVM}^{\mathrm{a}}$ checked & 40 & 60 \\
\hline Unopened vials returned to refrigerator & 100 & 100 \\
\hline Unopened vials returned to USE FIRST ${ }^{\mathrm{b}}$ box & 20 & 80 \\
\hline Opened vials discarded & 90 & 100 \\
\hline Vaccine stock for next session & 40 & 50 \\
\hline \multicolumn{3}{|l|}{ Cold chain management } \\
\hline Icepacks conditioned & 0 & 80 \\
\hline Freeze indicator checked & 40 & 90 \\
\hline Carrier conditioned icepacks & 0 & 80 \\
\hline Carrier vaccine vials in middle & 70 & 70 \\
\hline Carrier pad on top & 30 & 70 \\
\hline Carrier lid closed tightly & 40 & 80 \\
\hline \multicolumn{3}{|l|}{ Session equipment } \\
\hline $\mathrm{AD}^{\mathrm{c}}$ syringes collected & 100 & 100 \\
\hline Reconstitution syringes collected & 90 & 90 \\
\hline Safety box collected & 100 & 100 \\
\hline AEFI $^{\mathrm{d}}$ medications collected & 40 & 50 \\
\hline Permanent register collected & 100 & 100 \\
\hline Daily register collected & 90 & 100 \\
\hline New cards collected & 100 & 100 \\
\hline \multicolumn{3}{|l|}{ Card review and registration } \\
\hline Review $\mathrm{DOB}^{\mathrm{e}}$ and age & 90 & 100 \\
\hline Review vaccines previously received & 70 & 100 \\
\hline Review vaccines eligible for & 90 & 90 \\
\hline Permanent register ID $^{\mathrm{f}}$ & 100 & 100 \\
\hline Permanent register DOB & 100 & 100 \\
\hline Permanent register address & 0 & 10 \\
\hline Permanent register date and dose of vaccine & 100 & 100 \\
\hline Permanent register date and dose of vitamin A & 80 & 60 \\
\hline Daily register vaccine dose & 100 & 100 \\
\hline Daily register vaccine information & 20 & 40 \\
\hline Card registered given vaccine & 100 & 100 \\
\hline
\end{tabular}




\begin{tabular}{|c|c|c|}
\hline Domains and ISP & $\begin{array}{l}\text { PHCs with pretraining standard } \\
\text { practices }(\%)\end{array}$ & $\begin{array}{l}\text { PHCs with posttraining standard } \\
\text { practices }(\%)\end{array}$ \\
\hline Card marked date of next immunization & 70 & 100 \\
\hline Summary report & 20 & 40 \\
\hline Children missed vaccination listed & 80 & 40 \\
\hline \multicolumn{3}{|l|}{ Communication with clients and caregivers } \\
\hline Client and caregiver greeted & 70 & 60 \\
\hline Messaged date of next visit & 50 & 70 \\
\hline Messaged AEFI & 40 & 50 \\
\hline Messaged what to do in AEFI & 40 & 40 \\
\hline \multicolumn{3}{|l|}{ Vaccine preparation and administration } \\
\hline Wash hands with soap & 10 & 60 \\
\hline Vaccine prepared on clean table & 90 & 90 \\
\hline Reconstituted with correct type of diluent & 100 & 100 \\
\hline Reconstituted with correct quantity of diluent & 90 & 100 \\
\hline Reconstituted with new disposable needle and syringe & 80 & 100 \\
\hline Reconstitution needle and syringe disposed in safety box immediately & 70 & 90 \\
\hline Membrane or opening not touched & 40 & 90 \\
\hline Reconstituted vial in pad of vaccine carrier & 20 & 60 \\
\hline Fill syringe just before administration & 100 & 100 \\
\hline Alcohol not used & 100 & 100 \\
\hline Needle not touched & 90 & 90 \\
\hline Recommended technique & 50 & 90 \\
\hline Correct injection site & 50 & 90 \\
\hline Contraindication checked & 0 & 10 \\
\hline \multicolumn{3}{|l|}{ Waste management } \\
\hline AD syringe disposed immediately & 80 & 100 \\
\hline AD syringe disposed without recapping & 100 & 100 \\
\hline Safety box within reach of Staff & 80 & 100 \\
\hline Safety box closed when full & 100 & 100 \\
\hline Safety box out of reach of children & 30 & 20 \\
\hline
\end{tabular}

${ }^{a}$ VVM: vaccine vial monitor.

${ }^{b}$ USE FIRST: a box in the refrigerator to which unopened vaccine vials with acceptable VVMs should be returned at the end of the session to be used first in the next session.

${ }^{\mathrm{c}} \mathrm{AD}$ : auto-disable.

dAEFI: adverse event following immunization.

${ }^{\mathrm{e}} \mathrm{DOB}$ : date of birth.

${ }^{\mathrm{f}} \mathrm{ID}$ : identification.

\section{Discussion}

Six $(60 \%)$ of the studied sites showed significant improvement in ISPs following the training of their vaccinators. The most significant improvement was in the domains that got the lowest scores during the first assessment, which included: vaccine and diluent management, cold chain management, and vaccine preparation and administration. The posttraining assessment revealed an overall small improvement in ISPs' mean score, from 0.63 (SD 0.08) to 0.80 (SD 0.11), which might be related to what was concluded by one review evaluating the effects of educational meetings (eg, courses, conferences, lectures, workshops), in that any improvement they cause is most likely to be small [13].

All the studied PHCs were major ones (supposed to be run by physicians) and all were supplying immunization services through routine sessions on a regular basis. The observed number of vaccinators working in these sites is not relative to 
the number of people whom they serve. This might cause the quality of the provided health service to vary, because the imbalance in the supply, deployment, and composition of human resources may lead to a lack of equality in the provision of health services [14]. On the other hand, health care systems managing a balanced provider workload and staff mix may result in better patient care delivery [15].

Ten $(24 \%)$ of the vaccinators were new to working in immunization units, with an average service duration of less than one year. Thus, it was expected that those vaccinators would be less competent as they had less practical work experience [6]. While training could improve their professional practice and the health care outcomes for their patients [13], lack of training for 27 (64.3\%) of the vaccinators might seriously affect their competence, thus resulting in low quality practices.

The two PHCs that showed decline following training were further assessed to discover the causes behind it. One of these PHCs was unexpectedly supplied with a large quantity of influenza vaccine, and to dispense the vaccine as fast as they could the vaccinators decided to vaccinate everybody attending the PHC, regardless of their risk status for influenza. The posttraining assessment was implemented during this time, while many people were inside the immunization room with no control over their entry or presence, which negatively affected vaccinators' performance. In the second PHC, two of the three trained vaccinators were immediately moved away following the training and were replaced by only one of the newly assigned staff. Thus, the immunization unit lost much of its workforce as well as the skills gained from the training, which had an obvious adverse effect on the vaccinators' performance and on ISPs.

The three significantly improved domains were those dealing with aspects related to the vaccine itself: handling, storage, preparation, and administration. Practices under these domains might be considered (from vaccinators' perspectives) the most important and might have the most major consequences on the vaccinees. Other practices that might be considered of less serious impact showed a less remarkable, statistically nonsignificant improvement. The impact of educational meetings may be smaller for outcomes that health professionals may perceive as not having serious consequences for patients compared to outcomes that they may perceive as having moderately or highly serious consequences for patients [13]. On the other hand, our training was supported by three video clips as well as many pictures dealing with the practices belonging to the three most improved domains, which might help the vaccinators be more competent in these areas.
The WHO states that ice pack conditioning is a process that takes time and advanced planning, but cold chain surveys have shown that this practice is widely ignored [16]. This was the exact situation in our settings, revealing that ice pack conditioning was the most problematic among cold chain practices.

Adrenaline was not available in half of our sites even following the training, even though it is the responsibility of the health district to supply its PHCs with these adverse events following immunization (AEFI) medications. Thus, for this practice to improve it might require the health district to include these drugs in its priority list that could be bought from the local market when they are not centrally supplied by the department of pharmaceuticals and medical equipment, a measure that the system never allows a PHC to do independently. Thus, this practice might be considered a complex behavior (complexity of behavior may depend on whether there was a need for change by the individual, a communication change, or a change in systems and thus, whenever a change in the system is required to change certain behavior, the latter might be considered more complex) that is unlikely to change much [13].

In one study conducted in the United Kingdom, they found that communication strategies to date have lacked clear evidence of efficacy in vaccination settings [17]. In our settings, communication with clients and caregivers only improved a little with training, which is like the results of another study conducted in Vietnam where $83.3 \%$ of health care providers do not communicate about vaccination when giving an injection [18].

From all of the above, we can conclude that ISPs were doing variably in our immunization sites before training, but none were being practiced to standard. Training of vaccinators was effective in improving some practices, especially those dealing with the technical aspect of vaccination (ie, vaccine management, cold chain management, and vaccine preparation and administration). However, it is important to remember that the pre- and posttraining assessments were each conducted during a single visit in any of the selected sites, which might be a limitation of the study. In addition, the vaccine coverage rate was not included in the study even though it is an important variable that might be correlated to ISPs, leaving open the possibility for another study to be conducted.

Therefore, we would recommend this training, after some refinement, for other PHCs in Wasit governorate and on the national level, as well as for other countries or settings that use the Arabic language, to improve vaccinators' abilities and thus ISPs.

\section{Acknowledgments}

The authors would like to acknowledge the Eastern Mediterranean Public Health Network (EMPHNET) for their technical support as well as UNICEF for their financial support for the training. We also acknowledge the support of Muataz Abbas, Kamal Abdulrazzaq, Abdulaal Chitheer, Anwar Noah, and Alaa Rahi during the implementation of this work.

\section{Conflicts of Interest}

None declared. 


\section{Multimedia Appendix 1}

Checklist for setting up the immunization session.

[PNG File $229 \mathrm{~KB}-$ Multimedia Appendix 1]

\section{Multimedia Appendix 2}

Checklist for the conduct of the immunization session.

[PNG File 297 KB-Multimedia Appendix 2]

\section{Multimedia Appendix 3}

Checklist for concluding the immunization session.

[PNG File $137 \mathrm{~KB}-$ Multimedia Appendix 3]

\section{References}

1. World Health Organization: Vaccine Safety Basics. 2017. Module 1: Introduction to vaccine safety URL: https:/ /vaccine-safety-training.org/Importance-of-immunization-programmes.html [accessed 2019-01-05]

2. Rappuoli R. Vaccines: science, health, longevity, and wealth. Proc Natl Acad Sci U S A 2014 Aug 26;111(34):12282 [FREE Full text] [doi: 10.1073/pnas.1413559111] [Medline: 25299004]

3. Plotkin S, Orenstein W, Offit P. A short history of vaccination. In: Vaccines, 6th ed. Philadelphia: Elsevier-Saunders; 2013.

4. WHO, UNICEF, World Bank. State of the world's vaccines and immunization, 3rd ed. Geneva: World Health Organization; 2009.

5. World Health Organization. Measles: Fact sheet URL: http://www.who.int/mediacentre/factsheets/fs286/en/ [accessed 2019-01-05]

6. Nikula A, Rapola S, Hupli M, Leino - Kilpi H. Factors strengthening and weakening vaccination competence. International Journal of Nursing Practice 2009;15(5). [doi: 10.1111/j.1440-172x.2009.01781.x]

7. Burton A, Monasch R, Lautenbach B, Gacic-Dobo M, Neill M, Karimov R, et al. WHO and UNICEF estimates of national infant immunization coverage: methods and processes. Bull World Health Organ 2009 Jul;87(7):535-541 [FREE Full text] [doi: 10.2471/blt.08.053819] [Medline: 19649368]

8. Ministry of Health-Iraq, US Agency for International Development. Guidelines for the Workers in the Expanded Program on Immunization, 1st ed. Baghdad: Ministry of Health-Iraq; 2014.

9. WHO. Module 5: Managing an immunization session. In: Immunization in practice: A practical guide for health staff- 2015 update. Geneva: World Health Organization; 2015.

10. Mantel C. World Health Organization. Checklists for vaccines and immunization URL: http://www.who.int/pmnch/activities/ jointactionplan/tf2 checklists vaccines and immunization.pdf?ua=1 [accessed 2019-01-05]

11. Ministry of Health-Iraq, US Agency for International Development. Vaccine and Cold Chain Management in Health Institutions, 1st ed. Baghdad: Ministry of Health-Iraq; 2014.

12. Ministry of Health-Iraq, US Agency for International Development. Field Guideline for Adverse Events Following Immunization Surveillance, 1st ed. Baghdad: Ministry of Health-Iraq; 2014.

13. Forsetlund L, Bjørndal A, Rashidian A, Jamtvedt G, O'Brien M, Wolf F, et al. Continuing education meetings and workshops: effects on professional practice and healthcare outcomes. Cochrane Database Syst Rev 2009;2. [doi: 10.1002/14651858.cd003030.pub2]

14. WHO. Monitoring the building blocks of health systems: a handbook of indicators and their measurement strategies. Geneva: World Health Organization; 2010.

15. Mohr DC, Young GJ. Slack resources and quality of primary care. Med Care 2012 Mar;50(3):203-209. [doi: 10.1097/MLR.0b013e318241e3e6] [Medline: 22193414]

16. PATH. 2013. Optimize: Preventing Freezing in Cold Boxes and Vaccine Carriers URL: http://www.path.org/publications/ files/TS opt handout freeze safe.pdf [accessed 2019-01-05]

17. Leask J, Kinnersley P, Jackson C, Cheater F, Bedford H, Rowles G. Communicating with parents about vaccination: a framework for health professionals. BMC Pediatr 2012 Sep 21;12:154 [FREE Full text] [doi: 10.1186/1471-2431-12-154] [Medline: 22998654]

18. Ngoc N, Hoàn V. Health Strategy and Policy Institute. Vietnam: Ministry of Health; 2009. Current Situation Assessment of Human Resources in the Expanded Program of Immunization URL: https://tinyurl.com/y3sntwxz [accessed 2019-01-05]

\section{Abbreviations}

AD: auto-disable

AEFI: adverse event following immunization

CDC: Centers for Disease Control and Prevention 
DOB: date of birth

EMPHNET: Eastern Mediterranean Public Health Network

HCW: health care worker

ID: identification

ISP: immunization session practice

PHC: primary health care center

UNICEF: United Nations Children's Fund

VVM: vaccine vial monitor

WHO: World Health Organization

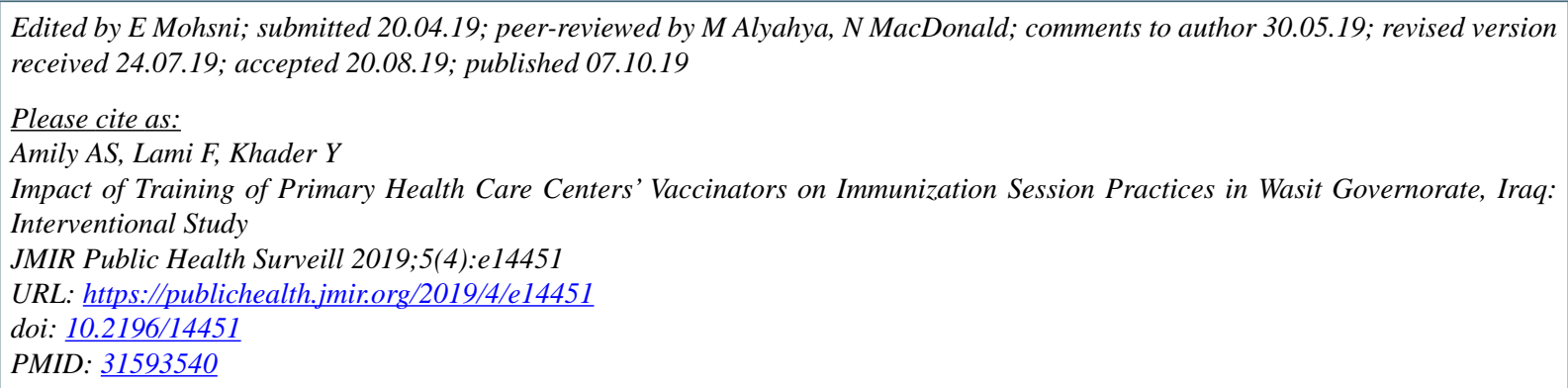

(C)Ali Sadiq Amily, Faris Lami, Yousef Khader. Originally published in JMIR Public Health and Surveillance (http://publichealth.jmir.org), 07.10.2019 This is an open-access article distributed under the terms of the Creative Commons Attribution License (https://creativecommons.org/licenses/by/4.0/), which permits unrestricted use, distribution, and reproduction in any medium, provided the original work, first published in JMIR Public Health and Surveillance, is properly cited. The complete bibliographic information, a link to the original publication on http://publichealth.jmir.org, as well as this copyright and license information must be included. 